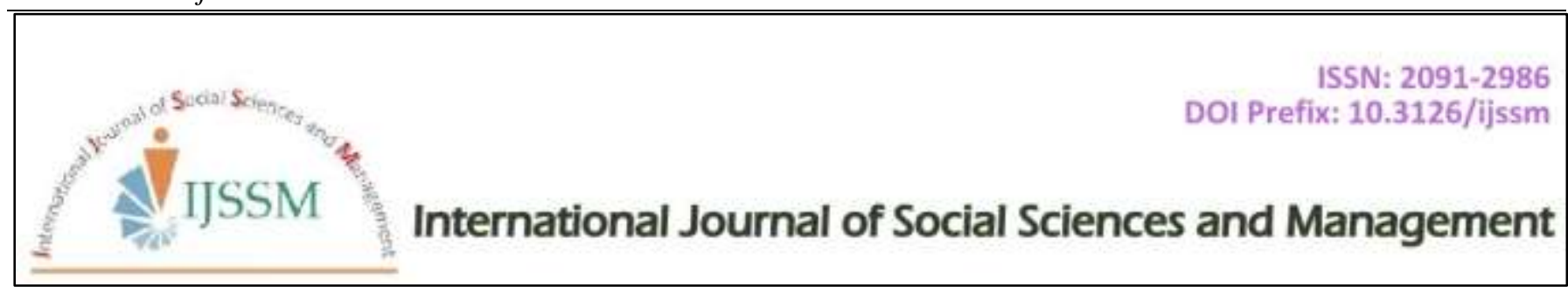

Research Article

\title{
The Sustainability Marketing Mix for Thai Senior Tourism
}

\author{
Nitchakarn Noo-urai ${ }^{1} *$ and Kaedsiri Jaroenwisan ${ }^{2}$ \\ ${ }^{1}$ Faculty of Management Sciences, Prince of Songkla University, Thailand \\ ${ }^{2}$ Faculty of Management Science, Silpakorn University, Thailand \\ *Corresponding author email: nitchakarn156@gmail.com
}

\begin{abstract}
This article was studied sustainability marketing mix strategy for Thai senior tourism. Collecting data through focus group discussion. The semi-structured interview used to collect data. The consequence of this research point out suitable product strategy for Thai senior tourism is the design of restroom with flush toilet with side-handrail and anti-slip floor material. In term of Price Strategy, sufficient accommodation cost is in range between 500 to 1,000 baht and entrance fee should not be over 100 baht. Place strategy is concentrated at accessible channel and attraction places information through internet, telephone, and word of mouth. Television media, used as Promotion Strategy, is most satisfactory media for Thai senior, which could be running period during 5:00 AM to 7:00 AM and 5:00 PM to 8:00 PM. In case of Participant strategy, traveling business is supposed to be emphasis on number of staff for this group of tourists that proper ration is a staff per three tourists. The Physical Evidence strategy is underline about decoration base on local identity and enough parking lot. And the process strategy is considered environmental prevention and protection which is use of clean energy or energy saving mechanic in accommodations. The packaging strategy is mention to package tour for senior tourist that provide conveniences and special services from expert staff. For programming strategy is religious festivals, traditional festivals, agriculture festivals, health festivals, etc. And partnership strategy is considered to highlight on business corporation to support Thai senior tourist services and build information center for senior tourists.
\end{abstract}

Keywords: sustainability marketing mix; sustainability marketing; marketing mix; marketing strategy; senior tourism

\section{Introduction}

Leading industrial countries are reaching aging society. Presently, global population is decreasing from 1.1 percentage to 0.86 percentage in year of $2020-2025$. Germany, Japan, and Russia population growth rate is below zero. Therefore, senior tourist trends increasing. The group of senior tourist have many readiness factors such as time, budget, decision independency of traveling spending which is more than middle age, saving money, interesting on health tourism, planning for long stay vacation. (Lieux et al.1994; Reid \& Bojanic, 2010; ministry of tourism and sports, 2011).

Thailand is also become to aging society that influences by extensive reduction of population and increasing of citizen life expectancy. Thai old age citizen annually rise about 473,000 people. Thailand will become complete aged society in 2013 and in year of 2035, Thailand population would gain more than 30 percent of current population - in
2013 Thailand population of over 60 -year-old was raised to 9.6 Million people (Foundation of Thai Gerontology Research and Development institute, 2014). The elderly population growth is caused by several determinants for example, mortality reduction and reproduction increment. Those influence factors lead to infrastructure transformation into aging society. On the other hand, the incremental of elderly population is significant affect to boost number of potential tourists that produce an effect of elderly tourist market expansion and attractive for business. Because senior tourism has varied range of leisure time, good health, higher income, independency of travel spending, and saving money (Reid \& Bojanic, 2010). As the result, this transformation influences a great impact on tourist behaviors and traveling style of each age range.

Sustainability marketing concept leads tourism market to be able to response and aware of society and environmental responsibility. The concept will also adept to paradigm shift which is focus on customer needs while concentrate on 
environmental protection and community collaboration. Moreover, business operation and management should evaluate three factors are economic factor, environmental factor, and society factor (Belz \& Peattie, 2012; Kumar et $a l ., 2012)$. In the long run, marketing will be influenced by several determinants such as technology and productivity growth in area of production processes and communication technology. Additionally, the incremental of society impact and environment impact by economy growth particularly chain reaction of climate change are going to drive business and marketers to study and research on sustainability idea to maintain relationship and customer value delivery (Belz \& Peattie, 2012).

The challenge against social structure change establishes a group of senior tourist which is niche market with potential purchasing power. The increasing of Healthy trends and new traveling style promotion conform to need of senior tourist. There bring into the study of sustainability Thai senior tourist marketing aim to support and guide tourist market improvement in economic, social, and environment. As the result, the study focuses and explores sustainability marketing mix strategy for Thai senior tourist.

\section{Literature Reviews}

Marketing is functioned in business to review customer's consumption power and activate the need of product by using marketing tools. Business organization will be financial benefited when present product or goods that meet customer need and want. On the other hand, customer will be received satisfied product or goods in return and business organization gain a profit and growth that conduce towards increasing of employment. In term of materialism society, those logic is roughly looking good because it would be support and improve economy growth and significant factor for economic development. Nevertheless, there will be positive outcome in short term. The long term consumption will be seriously impact on account of resource consuming, particularly non-renewable resource such as water, natural gas, fuel, coal, and forest woods. Over-abundantly nonrenewable resource consumption will lead to natural disaster (Parsons \& Maclaran, 2009). Therefore, sustainability marketing is aim to manage organization, operation, and resourcing and marketing program control to meet customer's need and want while considering social and environment characteristic to achieve organization purposes and goals. The customer relationship, the social environment, and the natural environment are also required to build and sustain. (Belz \& Peattie, 2012).

Marketing mix is satisfied tool to influences customer demand of purchasing products or goods. (Bowie \& Buttle, 2011) Many researchers evidently demonstrate the difference between product and service. Some researchers believe traditional four P's approach consist of product, price, place, and promotion (Kotler \& Keller, 2006; Reid \&
Bojanic, 2010) that cannot be adapted with service industry. So there leads an improvement of traditional four P's approach for service industry to be more suitably on current situation (Reid \& Bojanic, 2010). According difference and similar points between traditional four P's approach and marketing mix, Reid \& Bojanic (2010) believe product component in marketing mix is expanded, human resource is one element of service's production process, and distribution channel will be established when customer has been appeared. Moreover, marketing research is also involved in marketing communication. In marketing mix, distribution's product pricing is consisted of location, atmosphere, and intermediary in the middle of employee and customer. Pomering et al. (2011) present concept of sustainable tourism's marketing mix for managing a tourism corporation's supply and demand side to fulfil the incensement of customer demand. Sustainability marketing elements indicate relationship between business value and stakeholders such as producer, customer, employee, market community, and environment. These are shown sustainability organization management purposes. Concept of marketing mix for sustainable tourism adapts the triple bottom line of economic factors, the environmental, and sociocultural concerns to interpret marketing mix concept. So marketing mix for sustainable tourism engages perspective of sociocultural concerns and environmental factors into traditional four P's approach to sustain organization that consist of 10P's.

Product can serve the needs and necessities of consumers or target audiences (Kotler et al., 2006) that business's target market offer combined of products and services to customer (Kotler \& Armstrong, 2014). Tourism products and services are comfort facilities or provided goods (Morrison, 2002). Efficiency energy consumptions, resources utilizations, environmental activities, and product designs are main factor for sustainability tourism products which concern about tourists and local community participation (Emery, 2012; Pomering et al., 2011).

Price is declared agreed condition or barter between producer and customer (Bowie \& Buttle, 2011). Generally, product value is determined by product price which sustainability product's price will contain overall ecological cost or capital. In addition, positive and negative environmental impacts are reflected through product price as well (Fuller, 1999). Premium prices are compatible with small group of sustainable tourism product. Nevertheless, sustainable pricing is calculated cost regarding economic, environment, and society that able to deliver value to customer and reasonable profit for organization (Martin \& Schouten, 2012). The decision making according sustainable premium pricing is possible when deliver distinctly understanding to customer for product and service's value which concerns environmental and sociocultural factors (Pomering et al., 2011). 
Place/Distribution for tourism industry, distribution channel is tourism products or services accessibility (Bowie \& Buttle, 2011). Alternative transportation or traveling method would will reduce environmental impact for sustainable place/distribution such as walking, traveling by boat, using local bus or train. There is also boost up sustainability of economic and community (Pomering et al., 2011).

Promotion is a tool for business to communicate and provides information to customers, tourists, staffs, and stakeholders (Bowie \& Buttle, 2011). For sustainable promotion will focus to communicate with customer and stakeholder such as communication regarding consideration of influence reduction in environmental and social culture in local area. Besides, environmental issue enlightenment for tourist will give support to an increment of positive environmental responsibility image in direct and indirect side on number of tourists (Middleton, \& Hawkins, 1998; Pomering et al., 2011; Fuller, 1999).

Participant is all individual who is delivered services and be influential in customer/user acknowledgement such as staffs, customers, and related individual on services (Morrison, 2002). In service procedure, customer interacts with service provider in business location. A good relationship between customer and service provider will brought to successful customer product purchasing. Customer mix and service quality consistency are significant part for deliver customer satisfaction. Moreover, internal marketing is need and supported logical expansion of marketing mix that purpose staffs are one of business stakeholder. Even though, stakeholder is also included host community, other people in community might not or be involved with tourism business. Friendly and politely interactions, or impropriated action will produce a good or bad user experiences. So, this is required a marketing to related participants such as staffs, customer, and others. These are one of service delivery processes (Middleton \& Hawkins, 1998).

Physical evidence consist of tangible business demonstration or location appearances such as landscape display, lighting, interior decoration, etc. Physical evidence is influential in customer believes and feeling on services and, as well, customer behaviour. Nevertheless, physical evidence has significant influence in place atmosphere and staff's service procedure (Bowie \& Buttle, 2011). Organization physical evidence management should reflect business purpose on natural resources conservation or natural resources consumption described local socialization and civilization such as using coconut lamp as interior decoration, using handmade textile covering table or decorate places, etc.

Process is methods, mechanisms, or activity flows to delivery services or operating procedure. Generally, production and consumption of services are produced at the same time. Marketing needs to be confident of their services that have sufficiently efficiency, friendly, and competency delivery processes to deliver services to customer (Pomering et al., 2011; Bowie \& Buttle, 2011). In the context of service the process consists of online booking system, alternative energy such as solar power or wind power, customer services, low-carbon emission transportation such as hybrid vehicles or electric tourist bus/coach, and sensor switches. Those are influencing tourist to recognizing the environmental and behavioural changes (Pomering et al., 2011).

Packaging is combination of element that related services and tourism which offer one price or bundling travel and tourism service. Packaging is proposed a convenience to tourists and services/businesses advantage competitive environment (Pomering et al., 2011; Morrison, 2002).

Programming is special activities, event, or program convinces or persuades customers to pay more and increase tourism packaging or services interesting. Programing mostly addresses in term of special events or festival season that express tourist area symbol or characteristic. However, special appeal would increase interesting of tourist programme. There also produces others issue such as waste problem, lot of tourists that caused local community dissatisfaction (Pomering et al., 2011; Tirca et al., 2009). Therefore, tourist activities or programme planning or design is supposed to concern in environmental and local community impact.

Partnership is a component that is associated with the concept of collaboration and network development refers to the interaction between the various groups that have been involved in the travel business. There conducts by rules or norms shared or common standards in tourism management to achieve specific goals together (Tirca et al., 2009). Partners will influence the success of the design activities and tour packages. Alliance for sustainable development took place from the development of the tourism value. Partners helps to promote awareness of environmental and social such as airline business, credit card business, hotel, etc. This will cause accessibility to customer/ travelers database or information more potential (Pomering et al., 2011, Morrison, 2002).

\section{Methods}

Qualitative research is used to gathering information by focus group discussion. The focus group discussion were conducted four times by regions that are six members of Tumbon Ban Suean Elderly Club - Pattalung Province, five members of Karaburi Elderly Club - Nakhon Ratchasima Province, ten members of Tambon Chainat Elderly Club Chainat Province, and eight members of Praw District Elderly Club - Chiangmai Province. Semi-structured interview is selected as a researching tool which themed 
questions following marketing mix for sustainability senior tourism.

Discussion participant's selection criteria is over sixty years old senior tourist whom interesting on traveling from their local residence area to short or temporary stay in another place. Traveling purpose will be focused on vacation, visiting family or relatives, conference or seminar, religious ceremony, and also include traveling for treatment and other duties that does not working purpose and study. The traveling for purchasing goods for sale is also not involved in this focus group discussion. Moreover, discussion participants are traveling domestically and internationally at least once in twelve months.

In term of qualitative research analysis, content analysis is using to classify information into categories base on characteristic or properties sharing. Then information was proceeding to gathering data by coding inductive for analyses pattern and meaning of study issues and topics.

\section{Results}

\section{Tourism product of attraction or accommodation}

Discussion result of this issue is point at facility design for senior tourism, which concerns about appropriate walkway such as suitable ramp for wheelchair, size of the ladder, caution symbol or mark of ladder, and toilet design for senior tourists that use non-slip materials on the bathroom floor or handrails beside toilet. Additionally, facilities knowledge or information poster regarding attraction or accommodation will lead to support senior tourist during their traveling.

"Significant points for senior tourism is safety and amenity. Traveling and tourism are improving our mental health by recognized other things that difference from our hometown. Personally, cleanness is my first priority that impress the visitor. However, when I stay at hotel, I would not know how to open air-condition or even lights. And as I said, safety card to open a hotel room's door for our safety and protection."

"When facilities design to suit for elderly tourist should be consider about ramp or staircase which is very important. Like the time we went to the Chiang Dao Caves, it has stepped up. We had more trouble. However, if it has a ramp or elevator platforms or facilities for the elderly, it would be great."

"At home, my son design a toilet which has washbasin nearby and easy to stand up. I went to many of gas stations that have toilets little difficult for the elderly. However, some gas stations have handrail in toilet and easily to get up."

\section{The price of travel or accommodation}

The discussion group point issue on price of the tourist location and accommodation which Thai senior tourist would consider the price of the tourist location and accommodation into two parts are accommodation price and fees or charges of attraction places. The price between 500-1000 baht are prefer range of accommodation price for Thai senior tourist. In determining the pricing strategy, attraction or accommodation should be given a clear price as the dialogue that;

"Accommodation costs should not exceed five hundred baht per head."

"I think five hundred baht is suitable price but it also depended on each place. If I stay in beautiful hotel or the place that have a lot of people, accommodation costs should not exceed two thousand baht"

"I had to sleep at the hotel for three thousand baht, but they have great facilities, great service, it's worth comparing to the service."

On the issue of payment of fees of attraction places. The fee for the tourist fee should not exceed one hundred baht as the dialogue that;

"If the price of admission to tourist is one hundred baht, I think I satisfy and able to pay for that. But if fee higher that one hundred baht or does not have any elderly discount. I think it too much expensive."

"Fee cost, I would consider of worthiness, attraction, location, or benefit. But I think fifty baht is best fee cost."

"Not exceeding one hundred baht, I think is proper. If fee price exceeds one hundred baht, I think it quite expensive."

\section{Place}

The discussion group in the distribution channel topic focuses on tourist destination's access routes and channels to reach out to the attraction or accommodation. The result found channels to get information or contract to travel place or accommodation for the elderly is trough Internet or website. Moreover, for tourists, the elderly who cannot use the internet. They use a way to gathering information of attraction or accommodation by inquiries from people who had to travel before or phone. For directions or access routes to the hotel or tourist attraction, the route should be large labeled that elderly tourists easily and clearly to see or notice as the dialogue that;

"When searching information or contact travel place or accommodation, I normally find it on the internet."

"I cannot not surf the internet, So I ask friends or relatives nearby attractions, or people who had to travel before. They will provide dinning/accommodation information to me"

\section{Promotion}

Discussion groups point issues of marketing promotion, the incentives for elderly travelers or senior tourist is the discount. In addition, the appropriate media for advertising, travel or accommodation to senior tourists is television 
because it is accessible and frequency of media exposure than another media that watching time is 5:00 to 7:00 am and 17:00 to 20:00. News is famously for senior tourist to receive information from media, including news that send to mobile, magazines, and internet as the dialogue that;

"Providing incentives such as a $10 \%$ discount card to seniors when traveling at hotel or travel destinations"

"The media often viewed or watch as the top is television, 2nd is mobile, Tourism Authority of Thailand magazine is 3rd"

"I frequently use the Internet. Sometimes friends tell you that. Then I find further information on the Internet"

"Mostly, I watch TV and read tourism column in magazine."

So, as the result that media which senior tourists prefer include mobile, TV, magazines or travel documents, and the Internet. Senior tourist access to media during the period as follows.

"In morning, I woke up to watch TV. And using the Internet. About 19:00 to 20:00, I watch news on TV including read a newspaper every day. I would like to watch the news from TNN channel"

"Wake up in the morning about 5:30 to 6:30 am to watch the news. I watch TV news at noon again. In evening, I will see again at 17:00. But I do not listen to radio. Channel 5 is my choice.

\section{Participants}

For those participating in the tour or tourism point in topic of should outnumber provides employees or staffs who provide services to senior tourist than other groups. The discussion found as the dialogue that;

"For elderly tourists, tourist attraction should be provided to employees who serve or service this target group more tourists or other groups."

"When organizing a senior tour program should be provided nanny to take care senior travelers. If you go against each other with no nanny, no one can help anyone. Young people need to be a nanny to encourage and support during the trip. Nanny needed in large tour groups. However, if traveling with their children, those children will care anyway."

"Nanny or nurse should be a proportion of three senior tourist to one nanny"

\section{Physical evidence}

The discussion groups mention about the decoration of the tourist accommodation that found physical environment of the tourist accommodation for Thai senior tourist is consist of the decorated place with a unique culture or unique in the region. Including the design of parking lot that should not far from tourist room. And a parking area should be enough to service for tourists as the dialogue that;

"The place is decorated by local cultural, makes a unique or identity of particular area such as north culture or south culture. This is also conserve or maintain the uniqueness of each local region. When we traveling, these could be experiences of local cultures, and area identities."

"Traveling is way to study and experience way of life, culture, or lifestyle in each community. Place should be decorated by local cultural. These could reflect the way of life in that community"

Therefore, an idea of decorated physical environment or traveling place by local cultural or community identity will cause a noteworthiness and difference in traveling place or accommodation competition. Furthermore, discussion group shared additional comments about parking lot as the dialogue that;

"Parking lot is one of necessary consideration point when traveling. If lack of parking space or no parking available, these could bring us to not visit places. Parking space should be located nearby accommodation."

\section{Process}

In content of tourist attraction or accommodation's service processes, discussion group shared and debated about considering energy saving or using clean energy in tourism service processes. Tourism service process that take into consideration of environmental conservation and have environmental conservation activity such as a collaboration of using and does not change new sheet and towel during staying in accommodation to saving water, electricity, and cleaning chemical as the dialogue that;

"Think about the environment in the travel or accommodation. I must mention energy consumption, using alternative energy, and clean energy because there would be reduce and protect environment. These could be differentiating from other places. If we stay for 2 nights, on second night, it could be used same sheet and tower because it does not dirty and helping the environment. On the other hand, it could be help hotel owner to saving their expenses in cleaning those stuffs."

"Energy saving such as using same bed sheet or towel. These could be saving water and reduce of using cleaning chemical. However, it would not exceed two days. Cleaning energy is essential when traveling."

"If owner offer 5-10\% discount when using same bed sheet or towel, it could persuade visitor or customer. In return, accommodation would be saving cleansing expenses and increasing customer loyalty."

\section{Packaging}

Discussion group according tourism packaging were mentioned packaging of tourist attraction or 
accommodation will lead to easiness of travel planning for Thai senior tourist because packaging planner or provider prepare their services and traveling plan for senior tourist. Moreover, Tour guide is normally included in the travel packaging which they are expert and have experiences about traveling location and facilities to support senior tourist during the trips as the dialogue that;

"Generally, I purchase tour package for international trip, but domestic tour will be considered for purchasing base on location and price. Once, I traveling with packaging providers they would plan for whole trip, which I would not be worried about it, just traveling following their plan and suggest. On the other hand, when we traveling by ourselves trip planning that we should know everything such as routing, accommodations, places, location, etc."

"I would love to purchase tour packaging. It is more convenience than traveling by others. I must self-manage about accommodation and routing if me self-traveling."

\section{Programming}

As the result of discussion group, accommodation and attraction place for traveling programming for Thai senior tourist should combine with activity or event about religious, local tradition, agriculture as the dialogue that;

"For a trip, we consider about special event, programming, or festival on that period because we want to be experienced and entertained new thing that does not have in our local area. Therefore, if we traveling during event or festival. These could be 2 benefits are traveling and experiencing in the same time."

"I'd love to. Especially, traveling in same time with religious event."

"For Kathin Ceremony, if I am available, I would love to go."

"In Northern of Thailand, there are 12 local traditions annually. I go and join every event"

\section{Partnership}

As discussion group, the characteristic of partnership should consist of three elements are 1 . Tourist information center for senior tourist is to provide information about attraction area and government/public accommodation service. 2 . Tourism Businesses and local community collaboration to correspond with group of senior tourist. And 3. Tourism Businesses and local community collaboration to engage local community to generates income from tourist and raise to sustainable development in tourism business especially for senior tourist as the dialogue that;

"If tourist information center were established more than this or have more collaboration between service provider and local community to support senior tourists. I think it would be good for senior tourist."
"If there have network or connection, it would be easier to gathering information about tourism information and accommodation from authority or governance. Or senior tourism policy to boots up and support senior tourist."

\section{Discussion}

Marketing mix for sustainability tourism for senior tourist discussion is classify as following topics.

\section{Product}

Product design for senior tourism in Thailand should have equipment and facilities suitable for elderly travelers, Cleaning of attraction or accommodation, and security of travel or accommodation that compliance with Pomering et al. (2011) and Morrison (2002) said, products include tourist attractions, service facilities, and tours services. Moreover, tourism products can be classified in services area such as hotel, restaurant, cruise, car renting, theme park, casino, etc. Nevertheless, Emery (2012) and Pomering et al. (2011) recommend Sustainable tourism products. Sustainable tourism products must be considered and used efficiency resources and energy, environmental design, and should be also considered about collaboration between tourist and community. There will lead to Sustainable tourism products. Likewise, Fuller (1999) said life cycle of the product ought to cause less pollution and minimum waste. It is a qualification of sustainable product and sustainable production process.

\section{Price}

Price determine or price setting for tourism of Thai senior tourist should have clearly price tag, suitable price with facilities or services, varies price range, and have flexible price for further negotiable. Booms \& Bitner (1980) and Borden (1984) believe price is the value of service from the customer's perspective and pricing should be reasonable, acceptable, or several price range. In addition, Fuller (1999) and Martin \& Schouten (2012) suggest, in general, price is a measure of the value of product. Sustainable pricing must include all ecological cost and should reflect positive and negative environmental characteristic. Sustainable pricing will be calculated on economic, environmental and social costs which can deliver value to customers and cause the business to make profits.

\section{Place}

Distribution channel and platform for Thai senior tourist should composed of convenient traveling route to access to tourist attraction or accommodation, transportation services to local attractions or accommodation, using clean energy or renewable energy with transportation services, providing information channel, contact point information, and accommodation reservation via internet and telephone. Accordance with opinion of Bowie \& Buttle (2011), for tourism, distribution channel or place is a term that used to describe the place or location to sell and service to customers or tourists who can access to tourism products. 
Similarly, Pomering et al. (2011) mentioned, traveling journey to attraction place and around attraction place, businesses need to be aware of harm and damage caused to environment and sociocultural around attraction place. Promoting alternatives or choice of traveling way for tourist with low impact on the environment or ecosystem such as walk, cruise, local bus or train. It also helps local economy and create sustainable communities.

\section{Promotion}

The marketing promotion for Thai senior tourist should include discounts campaign or sale promotion for elder tourist, advertise or announce through television, mobile phone, mobile devices, internet, and traveling magazines. Accordance with thought of Belz \& Peattie (2012), the growing of online media and proactive marketing sale promotion, especially the increasing of online social media usage, will allow tourist easily access to tourism information, download the brochures, collecting discount ticket in portable devices which portable or mobile devices are communication tools that also reduces impacts on environment.

\section{Participant}

Those participating in the services for Thai senior tourists should be polite and courteous in services, understanding elder tourist customer health and condition, have number of staffs enough and adequate with group of elder tourist and needs. Additionally, it should be considered about senior tourist travel or transportation with other passengers or group of tourist. As Pomering et al. (2011) said participant essential for tourism is employee or staff management especially acquiring or selection processes, training process, and human resource management. Human resource management is need to offer several services to meet customer and tourist needs. However, Middleton \& Hawkins (1998) recommended according participants in tourism services, a group of participants is including host community. The local community in travel attraction place is whether possibly part of local tourism business or not. Moreover, a polite and friendly interaction between local community and tourists are led to good experiences and vice versa. Therefore, marketing is suit communication an information for internal employees, customer, and external stakeholder such as local tourism community. These is one of Service Delivery process.

\section{Physical evidence}

In Thai senior tourist physical evidence or environment, there is need to be provided secured walk path, local cultural decoration, sufficient parking spaces, and building design where support for seniors and disabled tourists. Accordance with the opinion of Bowie \& Buttle (2011), physical evidence is tangible assets or external building such as landscape design, lighting decoration, and furnishings.
Physical evidence can influence customers believes and feelings about services. There is also effect customer behavior and staff service process. The design of physical environment should be considered seniors and disabled tourists which provided facility for mobility purpose. Besides, Buhalis (2000) suggested the essential element of attraction appearance is community sustainability resources. The cultural design will enhance an appearance of its attraction places and surround.

\section{Process}

Service process for Thai senior tourists should be considered about using clean energy or renewable energy, automatic switch off in accommodation or room, availability of services for elderly tourists, early response in service process. Accordance with opinion of Pomering et al. (2011), in the content of service process, for instance, room or accommodation reservation through internet, using clean energy or renewable energy such as solar power or wind power in services which including low-emission and energy-efficient transportation, using automatic switch sensor to turn on and off lights, using sign that mention about energy saving such as a sign for reuse tower or sign for saving water usage. There are improve and increase customer and tourist involvement of environmental saving.

\section{Packaging}

A tourism packaging design for Thai senior tourist should be made easy and comfortable for customer or tourist, easily to travel planning, uncomplicated for budget planning, and involving expert and experienced staffs in tour. The successful tourism packaging design (Morrison, 2002) is tour package that have well-planning, good scheduling, and meet customer needs. Furthermore, Pomering et al. (2011) support a concept tour package bring about customer conveniences, produce competitive differentiation, and lead to efficient customer needs management and service production management.

\section{Programming}

Appropriate pattern of special event or festival for Thai senior tourist is special event or festival related with religion, culture and tradition, agriculture, and healthy. Morrison, 2002, emphasized design programming will develops special activities, event, or program that increase customer purchasing and interesting in packages or services. Mostly, it is appeared in term of special events or symbolic festival at tourist attraction. Nevertheless, in general of tour activity design or plan (Pomering et al., 2011) is one of tour packaging which produce an increasing of customer purchase and need, rising overall revenue, and shrinking an uncertainty according low season period. There causes employee hiring assurance during low season or non-tourist season. 


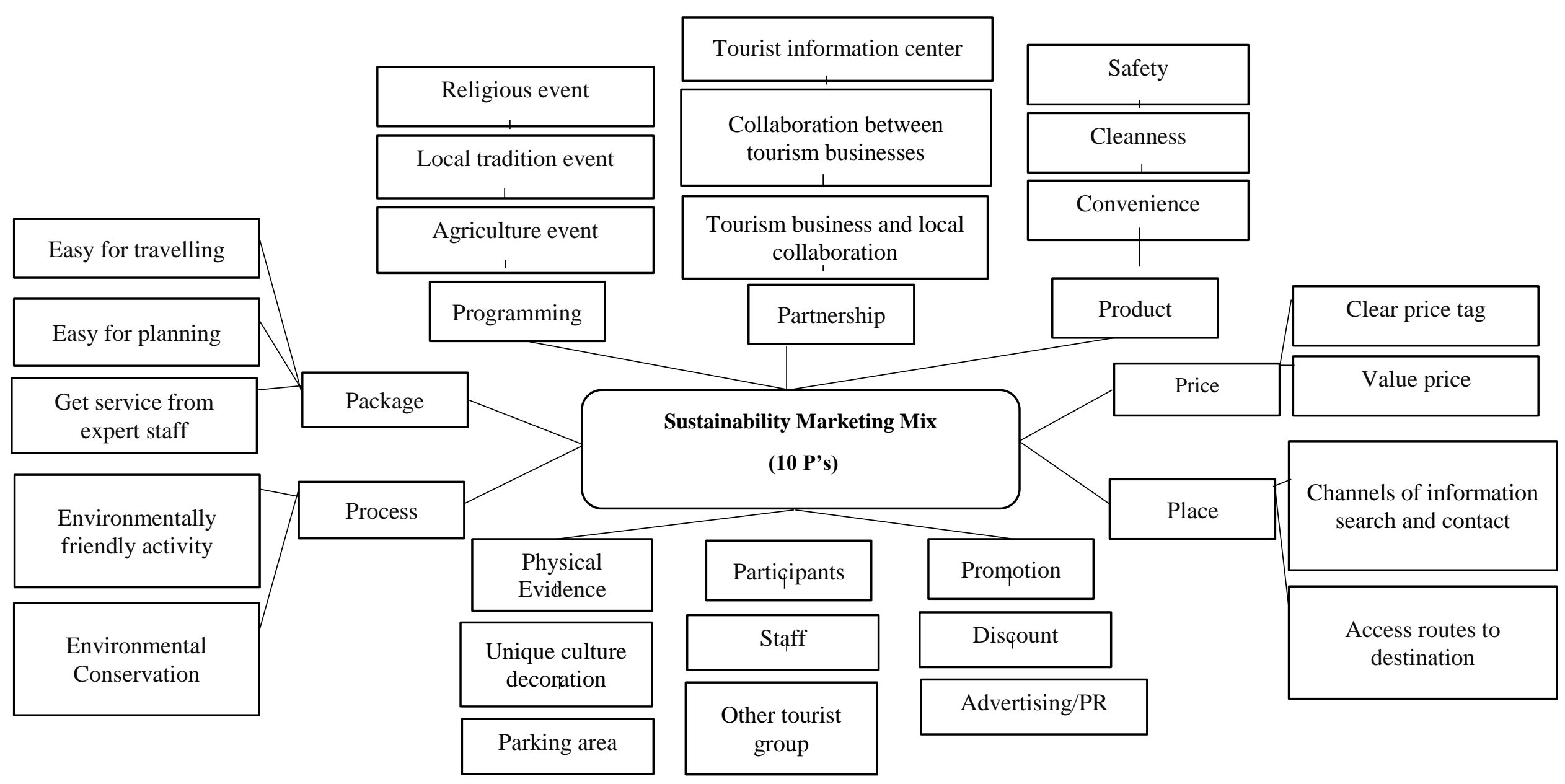

Fig. 1: The proposed model of Sustainability Marketing for senior tourism 


\section{Partnership}

Senior tourism partnership includes business-to-business partnership to contribute senior tourist service, business-tocommunity partnership to cause tourism sustainability, and business-to-government partnership to establish tourism information center for Thai senior tourist. Partners (Tirca et al., 2009) are the elements associated with concept of collaboration and network development. There is interaction activity between tourism business stakeholders through mutual agreement and standard. A mutual agreement and standard produce specific accomplishment together in partnership. Partnership advances to aware of environmental and sociocultural impact of attraction place such as collaboration between airline business, credit card business, hotel business that use customer information and data together.

\section{Conclusion}

Thailand population structure becomes to senior society as the result of longer longevity and birth rates decline. There brings group of elderly population segment is importance for tourism because elderly population group is retirement group who have traveling time and income from pension or saving money. There causes an impact on tourism management to adapted with senior tourists. On the other side, the emergence of sustainable marketing concept gives an awareness of social and environment responsibility. While businesses can be profitable and competitiveness. Sustainability Marketing is extending perspective of traditional marketing as marketing tools to produce economic profit for business along with environmental conservation and social responsibility for business. Thereby, Sustainability Marketing for senior tourist is consist of 10P's is Product, Price, Place, Promotion, Participation, Physical evidence, Process, Packaging, Programming, Partnership. The study summarizes proposed model of Sustainability Marketing for senior tourism as following Fig. 1.

The study outcomes are expected to be beneficial to business services, travel, and accommodation according determining the marketing strategy for senior tourists and marketing strategies to produces sustainability for business. For next research recommendation is should be repeated on the point of the marketing mix of senior tourist sustainable tourism in Thailand in order to assure consistency of sustainability marketing mix for Thai senior tourism or study a concept of the sustainability marketing of foreign senior tourists, long stay tourist, or other group of tourist such as the eco-tourists and adventure tourists, health tourists, or a group of wedding and honeymoon tourists.

\section{Acknowledgments}

The authors would like to thank National Research Council of Thailand for financially supporting this research.

\section{References}

Aronsson L (2000) The development of sustainable tourism. Great Britain: Bath Press.

Belz F-M and Karstens B (2005) Strategic and instrumental sustainability marketing a conceptual framework. Marketing and management in the food industry. Retrieved from http://www.econbiz.de/archiv1/2010/104248_sustainabili ty_marketing_framework.pdf

Belz F-M (2005) Sustainability marketing: Blueprint of a research agenda. Marketing and management in the food industry. Retrieved from www.food.wi.tum.de

Belz F-M (2006) Marketing in the 21st Century. Business Strategy and the Environment 15: 139-144.

Belz F-M and Peattie K (2012) Sustainability Marketing: a global perspective (2nd ed.). UK: John Wiley \& Sons,Ltd.

Booms BH, and Bitner MJ (1980) New management tools for the successful tourism manager. Annals of Tourism Research 7: $337-352$.

Borden NH (1984) The concept of marketing mix. Journal of Advertising Research 2: 7-12.

Bowie D and Buttle F (2011) Hospitality Marketing Principles and Practice (2nd ed.). Spain: Elsevier.

Buhalis D (2000) Marketing the competitive destination of the future. Tourism Management 21: 97-116.

Charter M, Peattie K, Ottman J and Polonsky MJ (2002) Marketing and sustainability. Retrieved form http://www.cfsd.org.uk/smart-know-net/smart-knownet.pdf

Emery B (2012) Sustainable Marketing. England: Pearson Education Limited.

Foundation of Thai Gerontology Research and Development institute (2014) Situation of Thai elderly 2013. Retrieved from

http://www.ipsr.mahidol.ac.th/ipsrbeta/FileUpload/PDF/ Report-File-504.pdf

Fuller DA (1999) Sustainable marketing: Managerial-Ecological issues. London: SAGE Publication, Inc.

Harris R and Leiper N (1995) Sustainable Tourism an Australian perspective. Sydney: Reed International Books Australia.

Huang L and Tsai H-T (2003) The study of senior traveler behavior in Taiwan. Tourism Management 24: 561-574.

Hunter C (1997) Sustainable tourism as an adaptive paradigm. Annals of Tourism Research 24: 850-867.

Jamrozy U (2007). Marketing of tourism: a paradigm shift toward sustainability. International Journal of Culture, Tourism and Hospitality Research 1: 117-130.

Jones P, Clarke-Hill C, Comfort D, and Hiller D (2008) Marketing and sustainability. Marketing Intelligence \& Planning 26: 123-130. 
Kotler P and Armstrong G (2014). Principles of marketing (15th ed.). NY: Pearson Education Inc.

Kotler P and Keller KL (2006) Marketing Management (12th ed.). NJ: Pearson Education Ltd.

Kotler P, Bowen JT, and Makens JC (2006) Marketing for hospitality and tourism (4th ed.). NJ: Pearson Education Inc.

Kumar V, Rahman Z, Kazmi AA and Goyal P (2012) Evolution of sustainability as marketing strategy: Beginning of new era. Procedia-Social and Behavioral Sciences 37: 482-489.

Lieux EM, Weaver PA and McClear KW (1994) Lodging preferences of the senior tourism market. Annals of Tourism Research 4: 721-728.

Martin D and Schouten J (2012) Sustainable Marketing. NJ: Pearson Education Inc.

Middleton VTC and Hawkins R (1998) Sustainable tourism: A marketing perspective. Great Britain: Martins the printers.
Ministry of Tourism and Sports (2011) National tourism development plan 2012-2016. Retrieved from http://www.tica.or.th/images/plan_tourism25552559/2555-2559.pdf

Morrison AM (2002) Hospitality and travel marketing (3rd ed.). NY: Thomson Learning, Inc.

Parsons E and Maclaran P (2009) Contemporary issues in marketing and Consumer Behaviour. MA: ButterworthHeinemann.

Pomering A, Noble G and Johnson W (2011) Conceptualising a contemporary marketing mix for sustainable tourism. Journal of Sustainable Tourism 8: 953-969.

Reid DR and Bojanic CD (2010) Hospitality marketing management (4th ed.). NJ: John Wiley \& Sons, Inc.

Tirca AM, Stanciulescu GC and Chis A (2009) Heritage tourismA marketing focused approach. Paper presented at the Marketing-from information to decision (2nd ed.), ClujNapoca, Romania. 